\title{
Near-infrared reflectance spectroscopy prediction of neutral detergent-soluble carbohydrates in timothy and alfalfa
}

\author{
Z. Nie, ${ }^{\star}$ G. F. Tremblay, $\dagger^{1}$ G. Bélanger, $\nmid$ R. Berthiaume,$\ddagger$ Y. Castonguay, $\uparrow$ A. Bertrand,$\dagger$ R. Michaud, $\dagger$ \\ G. Allard,§ and J. Han* \\ *Department of Grassland Science, College of Animal Science and Technology, China Agricultural University, Beijing, P. R. China, 100094 \\ †Agriculture and Agri-Food Canada, Quebec, Quebec, Canada G1V 2J3 \\ $\ddagger$ Agriculture and Agri-Food Canada, Sherbrooke, Quebec, Canada J1M 1 Z3 \\ §Université Laval, Québec, Québec, Canada G1K 7P4
}

\begin{abstract}
Carbohydrates in forage crops can be divided into neutral detergent-insoluble fiber and neutral detergentsoluble carbohydrates (NDSC); the latter includes organic acids (OA), total ethanol:water-soluble carbohydrates (TESC), starch, and neutral detergent-soluble fiber (NDSF). The accurate and efficient estimation of NDSC in forage crops is essential for improving the performance of dairy cattle. In the present study, visible and near-infrared reflectance spectroscopy (NIRS) were applied to evaluate the feasibility of predicting OA, TESC, starch, NDSF, NDSC, and all related constituents used to calculate these 5 carbohydrate fractions in timothy and alfalfa. Forage samples $(\mathrm{n}=1,008)$ of timothy and alfalfa were taken at the first and second harvests at 2 sites in 2007; samples were dried, ground, and then scanned (400 to 2,500 nm) using an NIRSystems 6500 monochromator. A calibration $(\mathrm{n}=60)$ and a validation $(\mathrm{n}=15)$ set of samples were selected for each species and then chemically analyzed. Concentrations of TESC and NDSC in timothy, as well as starch in alfalfa, were successfully predicted, but many other carbohydrate fractions were not predicted accurately when calibrations were performed using single-species sample sets. Both sets of samples were combined to form new calibration $(\mathrm{n}=120)$ and validation $(\mathrm{n}=30)$ sets of alfalfa and timothy samples. Calibration and validation statistics for the combined sets of alfalfa and timothy samples indicated that TESC, starch, and NDSC were predicted successfully, with coefficients of determination of prediction $\left(\mathrm{R}_{\mathrm{P}}^{2}\right)$ of $0.92,0.89$, and 0.93 , and a ratio of prediction to deviation (RPD) of $3.3,3.1$, and 3.6, respectively. The NDSF prediction was classified as moderately successful $\left(\mathrm{R}_{\mathrm{P}}^{2}=0.88, \mathrm{RPD}=2.8\right)$. The NIRS prediction of $\mathrm{OA}$
\end{abstract}

Received July 31, 2008.

Accepted December 12, 2008.

${ }^{1}$ Corresponding author: gaetan.tremblay@agr.gc.ca was unsuccessful $\left(R_{P}^{2}=0.38, R P D=1.3\right)$. All related constituents were predicted successfully $\left(\mathrm{R}_{\mathrm{P}}^{2}>0.90, \mathrm{RPD}>3.0\right)$ by NIRS except ethanol-insoluble residual $\mathrm{OM}$, with $\mathrm{R}_{\mathrm{P}}^{2}=0.75$ and $\mathrm{RPD}=1.9$. Our results confirm the feasibility of using NIRS to predict NDSC, its fractions, and other related constituents, except for $\mathrm{OA}$ and ethanol-insoluble residual $\mathrm{OM}$, in timothy and alfalfa forage samples.

Key words: alfalfa, near-infrared reflectance spectroscopy, neutral detergent-soluble carbohydrate, timothy

\section{INTRODUCTION}

Forage carbohydrates account for approximately 60 to $75 \%$ of the total carbohydrate intake for lactating dairy cows. Carbohydrates in ruminant diets can be divided into 2 principal constituents: NDF and NFC. Because these 2 constituents are divided based on their solubility in neutral detergent solution, the term neutral detergent-soluble carbohydrates (NDSC) is more appropriate to describe NFC (Hall et al., 1999; Figure 1 ). Neutral detergent fiber includes cellulose, hemicellulose, and lignin, whereas the predominant carbohydrates in NDSC are sugars, starch, and pectic substances. The NDSC also include organic acids (OA), fructans, and any other carbohydrates that are soluble in the neutral detergent solution with heat-stable $\alpha$-amylase. As a class, NDSC are considered to be approximately 98\% digestible (Van Soest, 1967), but their diversity precludes their use as a uniform nutritional fraction. A better understanding of how dairy cattle digest carbohydrates could lead to improved animal performance and contribute to more efficient nitrogen use (Leiva et al., 2000).

The system for partitioning NDSC proposed by Hall et al. (1999) is based on different extractions in neutral detergent solution and an ethanol solution. This method allows researchers to quantitatively evaluate feed concentrations of OA, starch, sugars (monosaccharides and 


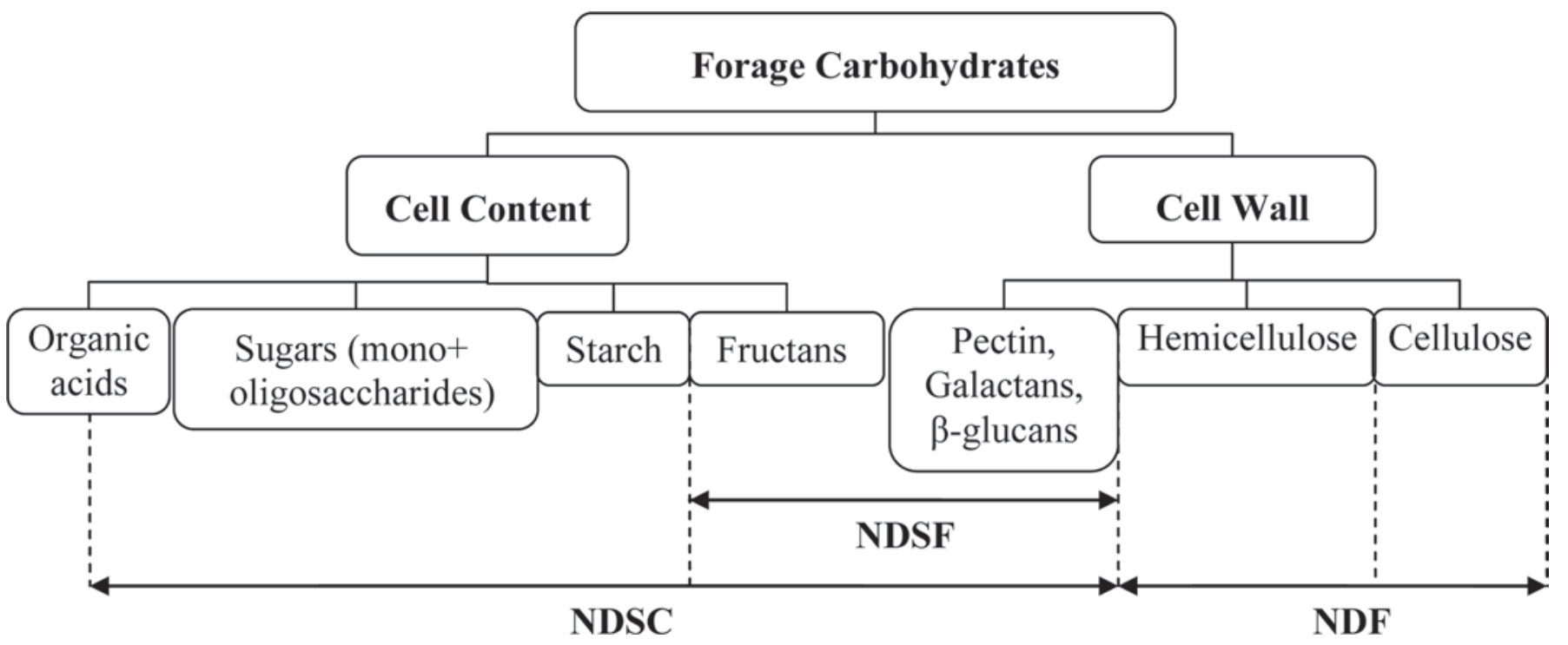

Figure 1. Forage carbohydrate fractions. NDSF $=$ neutral detergent-soluble fiber; NDSC = neutral detergent-soluble carbohydrates $($ Hall et al., 1999).

oligosaccharides), and neutral detergent-soluble fiber (NDSF), which includes fructans, pectic substances, galactans, and $\beta$-glucans (Figure 1). These 4 NDSC fractions are partitioned by their nutritional characteristics based on digestion in, or passage through, the rumen. The ability to measure these major carbohydrate fractions will help optimize the use of feed carbohydrates and other nutrients, thereby ensuring that all necessary metabolizable nutrients are provided to meet the nutrient requirements of cows for maintenance and production while reducing nutrient excretion to the environment.

Since the report by Norris et al. (1976) first appeared, near-infrared spectroscopy (NIRS) has been widely used to analyze the nutritive components (CP, NDF, etc.) of animal feed. This method combines the advantages of minimal sample preparation and rapid reporting times. Various carbohydrates have been estimated in feed by using NIRS (Roberts et al., 2004), including starch in corn silage (Welle et al., 2003) and grains (Kim and Williams, 1990), and pectin in legumes and grasses (Fairbrother and Brink, 1990). Fonseca et al. (1999) used NIRS to predict NDSF in alfalfa. Watersoluble carbohydrates and total NSC are frequently measured in alfalfa (Brink and Marten, 1986; Gossen, 1994) and in other grasses and cereal straws (Brown et al., 1987; Fairbrother and Brink, 1990). Batten et al. (1993) reported that NIRS can be used to predict NSC, which are usually determined with traditional chemical methods in shoot samples of rice and wheat crops. Mentink et al. (2006) studied the accuracy of NIRS prediction for the NFC concentration in TMR analyzed according to the method of NRC (2001). To date, there has been no report using NIRS to predict the different carbohydrate fractions determined by the method of Hall et al. (1999) in nonfermented dried forage samples. The objective of the current study was to evaluate the feasibility of using NIRS to predict concentrations of OA, starch, sugars, NDSF, and NDSC (and all related constituents used to calculate these fractions) in timothy and alfalfa forages.

\section{MATERIALS AND METHODS}

\section{Samples}

Experimental plots of alfalfa (Medicago sativa L. cv. AC Caribou) and timothy (Phleum pratense L. cv. AC Alliance) were established in 2006 at 2 sites (Lévis, $46^{\circ} 47^{\prime} \mathrm{N}, 71^{\circ} 12^{\prime} \mathrm{W}$; Normandin, $48^{\circ} 51^{\prime} \mathrm{N}, 72^{\circ} 32^{\prime} \mathrm{W}$ ) within the province of Quebec, Canada. There were 144 timothy and 144 alfalfa plots at each site. The size of each plot was $1 \times 1.5 \mathrm{~m}$. In 2007, forage samples were taken every $2 \mathrm{~h}$ from 0600 to $2000 \mathrm{~h}$ for $6 \mathrm{~d}$ during spring growth and summer regrowth at both sites, except that no timothy samples were taken during summer regrowth at Normandin. For each species at each site, the experimental design was a split plot with 3 replicates; the $6 \mathrm{~d}$ of harvest represented the main plots and the 8 sampling hours during the day represented the subplots. At each sampling time, approximately $250 \mathrm{~g}$ of fresh forage was cut to a $5-\mathrm{cm}$ height by using $100-\mathrm{mm}$ cordless grass shears (model UM1000D, Makita Electric Works Ltd., Anjo, Aichi, 
Japan). Forage samples were immediately placed in a large forced-air oven at $55^{\circ} \mathrm{C}$ for $48 \mathrm{~h}$. Dried samples were ground in a Wiley mill (Arthur H. Thomas Corp., Philadelphia, PA), passed through a 1-mm screen, and then stored in plastic containers.

All dried forage samples $(\mathrm{n}=1,008)$ were scanned over 400 to 2,498 $\mathrm{nm}$ at 2-nm intervals using an NIRSystems 6500 monochromator (Foss, Silver Spring, $\mathrm{MD})$. For each spectrum, principal component analysis scores were calculated using WinISI III software (version 1.61, Infrasoft International LLC, Silver Spring, $\mathrm{MD})$. Seventy-five samples were selected based on these scores, to form a calibration set $(\mathrm{n}=60)$ and a validation set $(n=15)$ of samples for each forage species. The calibration set of timothy samples was subsequently combined with the corresponding set of alfalfa samples to form a new calibration set $(\mathrm{n}=120)$. Validation sets from both these single species were also combined to form a new validation set $(\mathrm{n}=30)$. The similarity among samples within the combined sample sets was analyzed with a 3-dimensional plot of the principal component scores and the Global H statistic (WinISI III software, version 1.61, Infrasoft International LLC). Although the 3-dimensional plot indicated a slight clustering of the 2 species, all but 5 samples had a Global $\mathrm{H}$ score of $<3.0$, indicating that alfalfa and timothy did not constitute 2 different clusters of data.

\section{Chemical Analyses}

Seventy-five samples of each species (timothy and alfalfa) selected for NIRS calibration and validation were analyzed for carbohydrate fractions by using wet chemistry procedures (Hall et al., 1999). Neutral detergent-soluble carbohydrates and all related constituents were analyzed in several steps: 1 ) whole forage samples were analyzed for DM, OM, CP, and crude fat (ether extract, $\mathbf{E E}$ ); 2) whole forage samples were solubilized in an $80 \%$ ( $\mathrm{vol} / \mathrm{vol})$ ethanol:water solution, and the ethanol-insoluble residues (EIR) were analyzed for OM (EIROM), CP (EIRCP), and starch, whereas the ethanol-soluble extracts (ESE) were analyzed for total $80 \%$ ethanol-soluble carbohydrates (TESC), which also represented sugars (monosaccharides and oligosaccharides); and 3) whole forage samples were solubilized in a neutral detergent solution, and the neutral detergent residues (NDR) were analyzed for OM (NDROM) and CP (NDRCP).

Dry matter was determined by drying forage samples at $105^{\circ} \mathrm{C}$ for $24 \mathrm{~h}$. The $\mathrm{OM}$ was determined as the difference in sample weight before and after ashing at $200^{\circ} \mathrm{C}$ for $2 \mathrm{~h}$ and at $500^{\circ} \mathrm{C}$ for $4 \mathrm{~h}$ in a muffle furnace. Ether extract was determined using an Ankom XT Extractor (Ankom Technology Corp., Macedon, NY) in accordance with American Oil Chemists' Society official procedure Am 5-04 (AOCS, 1998). The NDF concentration was determined according to the procedure of Goering and Van Soest (1970), using sodium sulfite, $\alpha$-amylase, and the Ankom Fiber Analyzer (Ankom Technology Corp., Fairport, NY). The NDR was kept and further analyzed for OM and total nitrogen concentration. The ESE and EIR were obtained according to Hall et al. (1999). The TESC concentration in the ESE was determined by the phenol-sulfuric acid method (Hall et al., 1999). The EIR remaining after extraction was washed twice with methanol and used for starch quantification as glucose equivalent by using the $p$-hydroxybenzoic acid hydrazide method of Blakeney and Mutton (1980) after gelatinization at $100^{\circ} \mathrm{C}$ and digestion for $90 \mathrm{~min}$ with amyloglucosidase (Sigma A7255, Sigma Chemical Co., St. Louis, MO). Subsamples of $0.1 \mathrm{~g}$ of whole forage samples, NDR, and EIR were mineralized by using a mixture of $\mathrm{H}_{2} \mathrm{SO}_{4}$ and $\mathrm{H}_{2} \mathrm{SeO}_{3}$ as described by Isaac and Johnson (1976), and then total nitrogen concentration of these extracts was measured (method 15-107-06-2E, Lachat Instruments, 2008) on a Lachat QuikChem 8000 flow injection autoanalyzer (Zellweger Analytics, Lachat Instruments Division, Milwaukee, WI). Concentrations of $\mathrm{CP}$ were calculated as total nitrogen $\times 6.25$. All constituents, except DM, were analyzed in duplicate for each sample.

The NDSF were calculated as follows: NDSF = $($ EIROM - EIRCP $)-($ NDROM - NDRCP $)$ - starch. Organic acids are soluble in aqueous ethanol and they are found in the ESE. The majority of the fat and some $\mathrm{CP}$ were coextracted with $\mathrm{OA}$; very little fat remained in the EIR after the ethanol solution extraction and acetone rinses. The OA was calculated as (OM - CP) - (EIROM - EIRCP) - EE - TESC. The NDSC is the sum of OA, TESC, starch, and NDSF (Hall et al., 1999), but by substituting OA and NDSF by the respective formulas noted above, we used the following calculation to estimate this fraction: $\mathrm{NDSC}=\mathrm{OM}-$ $\mathrm{CP}-\mathrm{EE}-(\mathrm{NDROM}-\mathrm{NDRCP})$.

\section{NIRS Calibration}

A modified partial least squares regression method was used to develop calibration equations with the full spectrum (Marten et al., 1983) for NDSC, the 4 major carbohydrate fractions (OA, TESC, starch, and NDSF), and all other related constituents including DM, OM, CP, NDF, EE, NDROM, NDRCP, EIROM, and EIRCP. To account for possible operator errors, a repeatability file was created by collecting 20 spectra per sample, using independently filled cups for each of 3 randomly selected samples of each forage species. To improve the calibration models, 14 spectral pretreatments 
were tested (WinISI III software, version 1.61, Infrasoft International). Two criteria were used to select the best spectral pretreatment parameters: simultaneous low standard errors of cross-validation and high coefficients of determination in cross-validation (1-VR). Four cross-validation groups were selected when developing the NIRS equations so as to choose the optimal number of terms and avoid overfitting (Shenk and Westerhaus, 1991).

\section{Data Analyses}

The standard error of laboratory (SEL) was defined as the standard error of variance between duplicates analyzed by the reference method. The SEL was calculated by using the following equation:

$$
\mathrm{SEL}=\sqrt{\frac{1}{\mathrm{n}} \sum_{i}\left(\mathrm{x}_{1}-\mathrm{x}_{2}\right)^{2}}
$$

where $\mathrm{x}_{1}-\mathrm{x}_{2}$ is the difference between duplicate measurements by the reference method on sample $i$. For each forage species, SEL for DM determination was estimated from duplicate analyses of 26 randomly selected samples. The SEL of calculated carbohydrate fractions (OA, NDSF, and NDSC) was estimated by using the following equation:

$$
\mathrm{SEL}_{\mathrm{y}}=\sqrt{\mathrm{SEL}_{\mathrm{a}}^{2}+\mathrm{SEL}_{\mathrm{b}}^{2}+\mathrm{SEL}_{\mathrm{c}}^{2}+\cdots}
$$

where $\mathrm{SEL}_{\mathrm{y}}, \mathrm{SEL}_{\mathrm{a}}, \mathrm{SEL}_{\mathrm{b}}, \mathrm{SEL}_{\mathrm{c}}, \cdots, \mathrm{SEL}_{\mathrm{n}}$ is the SEL of constituent $\mathrm{y}, \mathrm{a}, \mathrm{b}, \mathrm{c}, \cdots, \mathrm{n}$, and where the constituent $\mathrm{y}$ is calculated from other constituents a, b, c, ..., n (Harris, 1991). For a newly given parameter, the ratio of error range (RER) of the calibration set was computed by dividing the range of values (maximum - minimum) by the SEL for calibration samples. The new calibration RER value was calculated by a similar method for validating RER introduced in Williams (2001), but was based on a different sample set. A wide range and a low SEL for a given constituent in the calibration set resulted in a high RER value and an increased likelihood of obtaining successful NIRS equations. In addition to considering the effect of range of concentration, similar to the coefficient of variation (SD/mean), the RER (range of values/SEL) also included the laboratory errors, which have a strong effect on NIRS performance.

Selection of the NIRS equations was based mainly on the coefficients of determination of prediction $\left(\mathbf{R}_{\mathbf{P}}^{2}\right)$ and standard errors of prediction (SEP) corrected for bias $[\operatorname{SEP}(\mathbf{C})]$. The $\operatorname{SEP}(\mathrm{C})$ was calculated by the following formula (Naes et al., 2002):

$$
\operatorname{SEP}(C)=\sqrt{\frac{1}{n-1} \sum\left(x_{i}-y_{i}-\operatorname{Bias}\right)^{2}},
$$

where $x_{i}-y_{i}$ is the difference between results obtained by the reference method $\left(\mathrm{x}_{\mathrm{i}}\right)$ and NIRS prediction $\left(\mathrm{y}_{\mathrm{i}}\right)$ for sample $\mathrm{i}$, and where the bias was calculated as follows:

$$
\operatorname{Bias}=\frac{1}{n} \sum\left(x_{i}-y_{i}\right),
$$

and $\mathrm{n}$ is the total number of samples in the test. The standard error of cross-validation is calculated in the same way as $\operatorname{SEP}(\mathrm{C})$ but is based on data from crossvalidation. The ratio of prediction to deviation $[$ RPD $=\mathrm{SD}$ of the validation set $/ \mathrm{SEP}(\mathrm{C})]$ was also considered for evaluating the accuracy of NIRS prediction. Basically, when the RPD was greater than 3, the NIRS equation was considered to be successful for analytical purposes in NIRS applications for agricultural products (Williams, 2001). In the current study, $\mathrm{R}_{\mathrm{P}}^{2}$ and RPD were used to classify the performance of a given NIRS equation according to Sinnaeve et al. (1994) and Williams (2001):

$$
\begin{gathered}
\text { Successful: } \mathrm{R}_{\mathrm{P}}^{2} \geq 0.90 \mathrm{RPD} \geq 3 \\
\text { Moderately successful: } 0.80 \leq \mathrm{R}_{\mathrm{P}}^{2}<0.902 .4 \leq \mathrm{RPD}<3, \\
\text { Unsuccessful: } \mathrm{R}_{\mathrm{P}}^{2}<0.80 \mathrm{RPD}<2.4 .
\end{gathered}
$$

The slope of regression between predicted and chemical values of each constituent for the validation set was also considered, especially when classifications based on the coefficient of determination and the RPD statistics were slightly different. As suggested by Williams (2001), a deviation of less than 0.05 for the slope value of 1.0 indicates successful NIRS equations.

\section{RESULTS AND DISCUSSION}

\section{Concentrations of Carbohydrate Fractions in Single Forage Species}

All mean concentrations of the carbohydrate fractions were greater in alfalfa than in timothy (Table 1), except for the TESC concentration, which was lower 
in alfalfa $(81.5 \mathrm{~g} / \mathrm{kg}$ of DM) than in timothy $(94.6 \mathrm{~g} /$ $\mathrm{kg}$ of $\mathrm{DM})$. The ranges of values for the 2 species were similar, except for the starch concentration, which had a smaller range for timothy (4.9 to $21.1 \mathrm{~g} / \mathrm{kg}$ of DM) than for alfalfa (4.0 to $90.5 \mathrm{~g} / \mathrm{kg}$ of DM). The higher standard deviation values of carbohydrate fractions in timothy confirmed that they varied more than the alfalfa samples, except for starch, with a standard deviation value of $3.6 \mathrm{~g} / \mathrm{kg}$ of DM in timothy and $19.8 \mathrm{~g} /$ $\mathrm{kg}$ of DM in alfalfa (Table 1). The SEL values of the timothy samples were slightly less than those of the alfalfa samples. Concentrations of TESC, starch, NDSF, and NDSC in the timothy and alfalfa samples of the current study are within the range reported by Fonseca et al. (1999). However, the mean concentrations of OA in timothy $(25.0 \mathrm{~g} / \mathrm{kg}$ of DM) and alfalfa $(38.5 \mathrm{~g} / \mathrm{kg}$ of DM) were lower than the values reported by Hall et al. (1999) for timothy hay (44 g/ $\mathrm{kg}$ of DM) and for alfalfa leaves $(92 \mathrm{~g} / \mathrm{kg}$ of DM) and stems $(47 \mathrm{~g} / \mathrm{kg}$ of DM).

\section{NIRS Prediction of Carbohydrate Fractions with Separate Equations for Each Species}

The validation statistics of the NIRS calibration based only on timothy samples (Table 1) showed that TESC and NDSC concentrations were successfully predicted by NIRS with $\mathrm{R}_{\mathrm{P}}^{2}>0.90$ and $\mathrm{RPD}>3$. The OA, starch, and NDSF concentrations in timothy were predicted unsuccessfully, with $\mathrm{R}_{\mathrm{P}}^{2} \leq 0.53$ and $\mathrm{RPD} \leq 1.4$. In alfalfa, the only successful NIRS equation was obtained for starch, with an $\mathrm{R}_{\mathrm{P}}^{2}$ of 0.93 and an RPD of 3.8. The calibration equations in alfalfa were moderately successful for TESC $\left(R_{P}^{2}=0.88, R P D=2.8\right)$ and unsuccessful for $\mathrm{OA}, \operatorname{NDSF}\left(\mathrm{R}_{\mathrm{P}}^{2} \leq 0.34, \mathrm{RPD} \leq 1.2\right)$, and NDSC $\left(R_{P}^{2}=0.77, R P D=2.1\right)$. The 3 successful NIRS equations based on individual forage species were strongly related to the relatively high $\mathrm{SD}$ values in the validation sets: $17.4 \mathrm{~g} / \mathrm{kg}$ of DM for TESC and $44.2 \mathrm{~g} /$ $\mathrm{kg}$ of DM for NDSC in timothy, and $10.6 \mathrm{~g} / \mathrm{kg}$ of DM for starch in alfalfa.

Accurate NIRS predictions require 3 basic conditions: 1) intense absorbance or sensitive variation of characteristic chemical bonds, such as $-\mathrm{NH},-\mathrm{CH}$, and $-\mathrm{OH}$ in the NIR region; 2) low laboratory errors, and; 3) a sufficient concentration (higher than $1 \mathrm{~g} / \mathrm{kg}$ of DM) and range of constituent concentrations (Shenk and Westerhaus, 1994; Nie et al., 2008). In the current study, the first requirement was not the principal limiting factor because, characteristically, all the chemical bonds of most constituents were mainly composed of

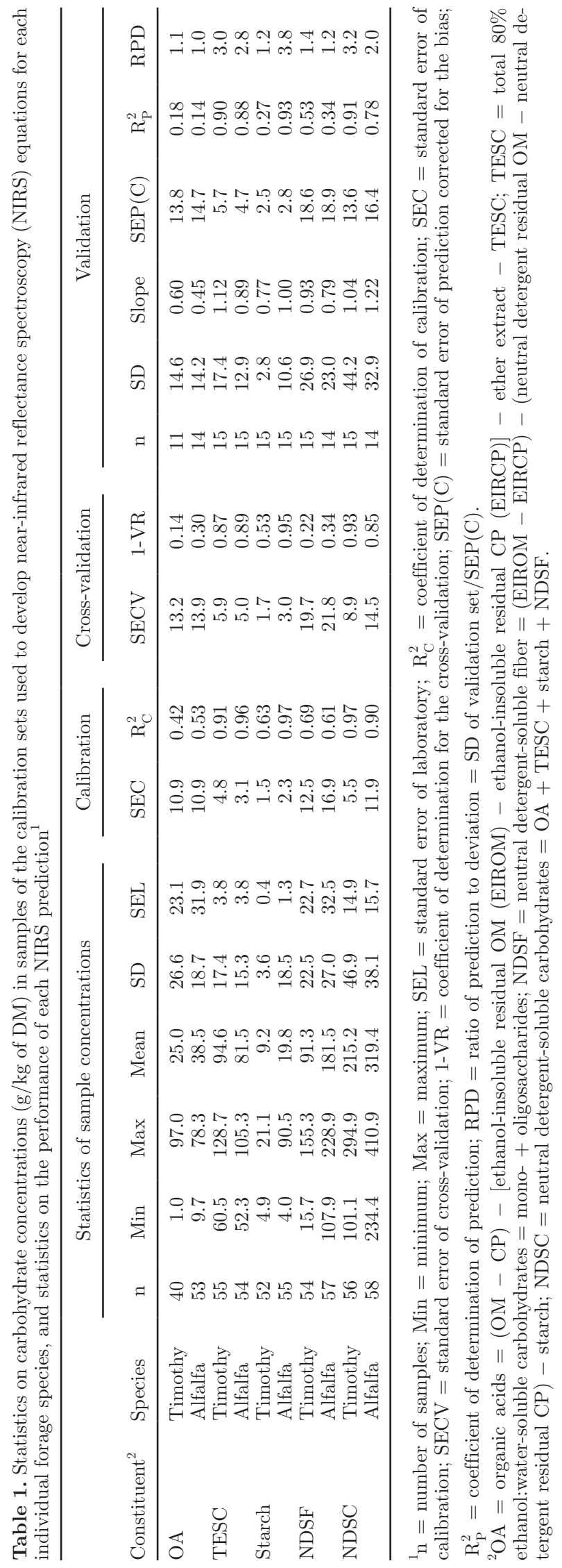


Table 2. Statistics on chemical concentrations ( $\mathrm{g} / \mathrm{kg}$ of DM) in samples of the calibration set used to develop near-infrared reflectance spectroscopy (NIRS) equations for the combined sample sets of alfalfa and timothy, and statistics on the performance of each NIRS prediction ${ }^{1}$

\begin{tabular}{|c|c|c|c|c|c|c|c|c|c|c|c|c|c|}
\hline Constituent $^{2}$ & $\mathrm{n}$ & Min & Max & Mean & $\mathrm{SD}$ & SEL & RER & Math treatment & $\mathrm{T}$ & SEC & $\mathrm{R}_{\mathrm{C}}^{2}$ & SECV & $1-\mathrm{VR}$ \\
\hline \multicolumn{14}{|c|}{ Major carbohydrate fraction } \\
\hline $\mathrm{OA}$ & 100 & 1.0 & 97.0 & 31.8 & 24.0 & 27.5 & 3.5 & $2,15,10,2$ & 5 & 12.7 & 0.41 & 14.4 & 0.27 \\
\hline Starch & 109 & 4.0 & 90.5 & 14.5 & 14.3 & 0.8 & 102.4 & $2,5,5,2$ & 10 & 1.6 & 0.97 & 2.6 & 0.93 \\
\hline NDSF & 111 & 15.7 & 228.9 & 137.5 & 51.6 & 27.5 & 7.7 & $2,5,5,2$ & 2 & 17.5 & 0.89 & 19.7 & 0.85 \\
\hline NDSC & 115 & 101.1 & 410.9 & 266.5 & 65.2 & 15.3 & 20.3 & $2,5,5,2$ & 5 & 12.2 & 0.96 & 13.8 & 0.95 \\
\hline \multicolumn{14}{|c|}{ Related constituent } \\
\hline $\mathrm{CP}$ & 113 & 87.7 & 251.6 & 169.5 & 34.7 & 9.7 & 16.9 & $1,4,4,1$ & 9 & 5.4 & 0.97 & 7.3 & 0.95 \\
\hline $\mathrm{NDF}$ & 114 & 213.3 & 683.2 & 419.5 & 138.3 & 12.6 & 37.3 & $2,15,10,2$ & 9 & 9.2 & 0.99 & 11.6 & 0.99 \\
\hline $\mathrm{EE}$ & 109 & 23.3 & 63.7 & 41.0 & 8.6 & 2.2 & 18.3 & $2,5,5,2$ & 9 & 1.7 & 0.96 & 2.4 & 0.92 \\
\hline NDROM & 110 & 265.3 & 680.5 & 444.2 & 107.0 & 11.2 & 37.2 & $2,10,10,2$ & 6 & 11.7 & 0.99 & 13.8 & 0.98 \\
\hline NDRCP & 115 & 6.1 & 59.7 & 21.8 & 14.8 & 1.2 & 46.6 & $2,5,5,2$ & 9 & 2.2 & 0.98 & 2.8 & 0.96 \\
\hline EIROM & 106 & 623.0 & 838.4 & 715.0 & 39.1 & 24.1 & 9.0 & $2,5,5,2$ & 4 & 13.3 & 0.85 & 14.8 & 0.81 \\
\hline EIRCP & 106 & 86.3 & 203.0 & 145.1 & 26.8 & 7.1 & 16.3 & $2,10,10,2$ & 4 & 5.9 & 0.95 & 6.9 & 0.93 \\
\hline
\end{tabular}

${ }^{1} \mathrm{n}=$ number of samples in the calibration set; Min = minimum; Max $=$ maximum; SEL $=$ standard error of laboratory; RER $=$ ratio of error range $=$ range of values (maximum - minimum) $/$ SEL of calibration samples; Math treatment $=$ the first number is the derivative order, the second number is the gap between derivatives, and the third and fourth numbers are the first and second smoothing; $\mathrm{T}=$ terms used in calibration equations; $\mathrm{SEC}=$ standard error of calibration; $\mathrm{R}_{\mathrm{C}}^{2}=$ coefficient of determination of calibration; SECV = standard error of cross-validation; 1 -VR = coefficient of determination for the cross-validation.

${ }^{2} \mathrm{OA}=$ organic acids $=(\mathrm{OM}-\mathrm{CP})-[$ ethanol-insoluble residual OM $(\mathrm{EIROM})-$ ethanol-insoluble residual $\mathrm{CP}(\mathrm{EIRCP})]-$ ether extract (EE) - TESC; TESC = total 80\% ethanol:water-soluble carbohydrates = mono- + oligosaccharides; NDSF = neutral detergent-soluble fiber $=($ EIROM - EIRCP $)-[$ neutral detergent residual OM $(\mathrm{NDROM})-$ neutral detergent residual CP $(\mathrm{NDRCP})]-$ starch; NDSC $=$ neutral detergent-soluble carbohydrates $=\mathrm{OA}+\mathrm{TESC}+$ starch + NDSF.

$-\mathrm{OH},-\mathrm{NH}$, and $-\mathrm{CH}$, which could be quantified exactly, as reported by Roberts et al. (2004). Furthermore, laboratory errors were controlled at an acceptable level, with a coefficient of variation between duplicate analyses of less than $5 \%$. However, the NIRS predictions in the current study, based on separate equations for each species, were still unsuccessful for many of the fractions (Table 1).

\section{NIRS Prediction with Combined Equations for Both Species}

To improve the NIRS performance by increasing the composition range and the standard deviations, as suggested by Dunn et al. (2002) and Cozzolino and Morón (2006), the calibration sets for timothy and alfalfa were combined to form a new calibration set, and the validation sets of the 2 species were also combined to form a new validation set. Compared with the calibration set of each species, ranges of values for NDSF and NDSC were greatly increased in the combined calibration set (Table 2). For instance, the NDSC concentration ranged from 101.1 to $294.9 \mathrm{~g} / \mathrm{kg}$ of DM in timothy and from 234.4 to $410.9 \mathrm{~g} / \mathrm{kg}$ of DM in alfalfa (Table 1), and by combining these 2 calibration sets, the range of values varied from 101.1 to $410.9 \mathrm{~g} / \mathrm{kg}$ of DM (Table 2 ). The ranges of values for 3 of the NDSC fractions (OA, TESC, and starch) in the combined species were close to those for each species. The standard deviation values of NDSF and NDSC in the combined calibration set were also greater than in the calibration set of each species. The standard deviation values of TESC and starch for the combined species were in between those for each species, whereas a lower standard deviation value was obtained for $\mathrm{OA}$ in the combined species (Tables 1 and 2).

Based on statistics of NIRS calibration, cross-validation (Table 2), and validation (Table 3 ) that used a combined sample set of both timothy and alfalfa, successful equations were obtained for all carbohydrate fractions and related constituents, except for OA and EIROM.

NIRS Prediction of Carbohydrate Fractions. When based on a combined sample set of both forage species, the NDSC concentration was successfully predicted by NIRS with a good degree of accuracy $\left(\mathrm{R}_{\mathrm{P}}^{2}=0.93, \mathrm{RPD}=3.6 ; \quad\right.$ Table 3$)$. The NDSC prediction for the combined set was improved, compared with the unsuccessful NIRS equation for alfalfa (Table 1). Mentink et al. (2006) reported a moderately successful NIRS equation for predicting NFC calculated according to the method of NRC (2001), with a coefficient of determination of 0.83 and an SEP of $15.5 \mathrm{~g} / \mathrm{kg}$ of DM in TMR. In the current study, the SEL associated with the analysis of NDSC in single calibration sets of timothy $(14.9 \mathrm{~g} / \mathrm{kg}$ of DM; Table 1$)$, alfalfa $(15.7 \mathrm{~g} / \mathrm{kg}$ of 
Table 3. Statistics of near-infrared reflectance spectroscopy prediction of the chemical composition ( $\mathrm{g} / \mathrm{kg}$ of $\mathrm{DM})$ for combined validation sets of timothy and alfalfa samples ${ }^{1}$

\begin{tabular}{|c|c|c|c|c|c|c|c|c|c|}
\hline Constituent $^{2}$ & $\mathrm{n}$ & $\mathrm{SD}$ & Mean & Bias & Slope & SEP & $\operatorname{SEP}(\mathrm{C})$ & $\mathrm{R}_{\mathrm{P}}^{2}$ & $\mathrm{RPD}$ \\
\hline \multicolumn{10}{|c|}{ Major carbohydrate fraction } \\
\hline $\mathrm{OA}$ & 25 & 16.4 & 27.1 & -8.3 & 0.96 & 15.1 & 12.8 & 0.38 & 1.3 \\
\hline Starch & 30 & 7.0 & 11.3 & 0.1 & 0.96 & 2.3 & 2.3 & 0.89 & 3.1 \\
\hline NDSF & 29 & 49.2 & 133.9 & 2.4 & 0.95 & 17.4 & 17.5 & 0.88 & 2.8 \\
\hline NDSC & 29 & 62.8 & 255.7 & -3.2 & 0.95 & 17.5 & 17.5 & 0.93 & 3.6 \\
\hline \multicolumn{10}{|c|}{ Related constituent } \\
\hline $\mathrm{CP}$ & 30 & 35.2 & 163.7 & 3.1 & 0.95 & 10.1 & 9.8 & 0.93 & 3.6 \\
\hline $\mathrm{NDF}$ & 30 & 140.5 & 435.3 & 0.3 & 0.96 & 16.4 & 16.7 & 0.99 & 8.4 \\
\hline $\mathrm{EE}$ & 28 & 7.5 & 39.1 & 0.0 & 1.01 & 2.2 & 2.3 & 0.91 & 3.3 \\
\hline NDROM & 30 & 104.5 & 463.7 & -3.4 & 0.91 & 23.9 & 24.1 & 0.96 & 4.3 \\
\hline NDRCP & 30 & 14.7 & 21.3 & -0.1 & 1.00 & 2.8 & 2.8 & 0.96 & 5.3 \\
\hline EIROM & 29 & 31.8 & 731.8 & 5.4 & 0.85 & 17.1 & 16.6 & 0.75 & 1.9 \\
\hline EIRCP & 30 & 22.7 & 138.8 & -0.3 & 0.86 & 6.9 & 7.0 & 0.93 & 3.2 \\
\hline
\end{tabular}

${ }^{1} \mathrm{n}=$ number of samples in validation set; SEP $=$ standard error of prediction; $\operatorname{SEP}(\mathrm{C})=$ standard error of prediction corrected for the bias; $\mathrm{R}_{\mathrm{P}}^{2}=$ coefficient of determination of prediction; $\mathrm{RPD}=$ ratio of prediction to deviation $=\mathrm{SD}$ of validation $\operatorname{set} / \mathrm{SEP}(\mathrm{C})$.

${ }^{2} \mathrm{OA}=$ organic acids $=(\mathrm{OM}-\mathrm{CP})-$ ethanol-insoluble residual OM $(\mathrm{EIROM})-$ ethanol-insoluble residual $\left.\mathrm{CP}(\mathrm{EIRCP})\right]-$ ether extract $(\mathrm{EE})-$ TESC; TESC $=$ total $80 \%$ ethanol:water-soluble carbohydrates $=$ mono- + oligosaccharides; NDSF $=$ neutral detergent-soluble fiber $=($ EIROM - EIRCP $)-[$ neutral detergent residual OM $($ NDROM $)-$ neutral detergent residual CP $(\mathrm{NDRCP})]-$ starch; NDSC $=$ neutral detergent-soluble carbohydrates $=\mathrm{OA}+\mathrm{TESC}+$ starch + NDSF .

DM; Table 1), and combined forage species $(15.3 \mathrm{~g} / \mathrm{kg}$ of DM; Table 2) were all calculated by using the formula described earlier (Harris, 1991) and were based on the SEL of OM, CP, EE, NDROM, and NDRCP. Therefore, the SEL of NDSC was not affected by the high SEL associated with the EIROM determination $(24.1 \mathrm{~g} / \mathrm{kg}$ of DM). This result could explain the more accurate prediction of NDSC than of OA and NDSF, which were both calculated from other fractions including EIROM. The NIRS prediction of TESC for the combined set of both species performed better $\left(\mathrm{R}_{\mathrm{P}}^{2}=0.92, \mathrm{RPD}=3.3 ;\right.$ Table 3$)$ than the successful NIRS equation for timothy and the moderately successful NIRS equation for alfalfa (Table 1). Mentink et al. (2006) report an unsuccessful calibration for TESC concentration in TMR with 1-VR of 0.61 and SEP of $13.8 \mathrm{~g} / \mathrm{kg}$ of $\mathrm{DM}$; this result was attributed to the high level of laboratory error associated with TESC analysis.

In the present study, however, although the $\mathrm{R}_{\mathrm{P}}^{2}$ value (0.89) of the NIRS prediction of starch concentration for the combined set was lower than 0.90, it was still classified as being successful, with an RPD of 3.1 and a high slope value of 0.96 . The starch NIRS prediction based on the combined species was considerably better than the starch prediction in timothy but was worse than that of alfalfa (Table 1). Similar successful NIRS predictions of starch concentration have been reported for corn silage (Kim and Williams, 1990; Welle et al., 2003).
In the current study, the worst NIRS calibration equation with the combined set was obtained for OA, with an $\operatorname{SEP}(\mathrm{C})$ of $12.8 \mathrm{~g} / \mathrm{kg}$ of $\mathrm{DM}$, an $\mathrm{R}_{\mathrm{P}}^{2}$ of 0.38 , and an RPD of 1.3 (Table 3); this result is similar to that obtained with the single species calibration sets. Because concentration of OA was calculated as (OM - CP) - (EIROM - EIRCP $)$ - EE - TESC, its SEL $(27.5 \mathrm{~g} / \mathrm{kg}$ of DM) was calculated from the SEL of all these constituents by using the formula presented above. The high SEL value led to the low RER value (3.5) for OA in the combined calibration set, which explains the difficulty of obtaining an accurate NIRS equation for OA (Table 2).

With an $\mathrm{R}_{\mathrm{P}}^{2}$ of 0.88 and an $\mathrm{RPD}$ value of 2.8 in validation (Table 3), the NIRS prediction of NDSF concentration in both timothy and alfalfa samples was classified as being moderately successful. The NDSF prediction with the combined set was much better than with timothy $\left(\mathrm{R}_{\mathrm{P}}^{2}=0.53, \mathrm{RPD}=1.4\right)$ and alfalfa samples $\left(\mathrm{R}_{\mathrm{P}}^{2}=0.34, \mathrm{RPD}=1.2\right.$; Table 1$)$. Fonseca et al. (1999) reported a successful NIRS prediction of NDSF $\left(\mathrm{R}^{2}=\right.$ $0.97)$ based on their alfalfa calibration $(\mathrm{n}=56)$ and validation $(\mathrm{n}=18)$ sets from a given harvest, but the prediction was less accurate $\left(\mathrm{R}^{2}=0.72\right.$ to 0.89$)$ when NIRS equations were based on samples from 4 other individual harvests or from combined harvests. The possible reason for the less accurate prediction for the combined set was attributed to insufficient sample 
variation because the $\mathrm{R}^{2}$ of NIRS equations was highly associated with the standard deviation values of calibration samples $(\mathrm{r}=0.99, P<0.01, \mathrm{n}=216$; Fonseca et al., 1999). In the current study, although the high SD $(51.6 \mathrm{~g} / \mathrm{kg}$ of DM) for NDSF was obtained by merging the 2 calibration sets of samples from 2 different forage species that were taken in 2 harvests at 2 sites, the $R_{P}^{2}$ of the NDSF prediction was still lower than 0.90. The $\operatorname{SEP}(\mathrm{C})$ of NDSF for the combined validation set (17.5 $\mathrm{g} / \mathrm{kg}$ of DM; Table 3) was also higher compared with the $\operatorname{SEP}(\mathrm{C})$ value reported by Fonseca et al. (1999), whereas the mean value for the combined calibration set $(137.5 \mathrm{~g} / \mathrm{kg}$ of DM; Table 2$)$ was lower than their mean NDSF concentration $(180.1 \mathrm{~g} / \mathrm{kg}$ of $\mathrm{DM})$. The limiting factor for obtaining accurate NIRS predictions of OA and NDSF was the high SEL value of $27.5 \mathrm{~g} / \mathrm{kg}$ of DM in both cases; this result was mainly due to the high SEL associated with the determination of EIROM $(24.1 \mathrm{~g} / \mathrm{kg}$ of DM; Table 2).

Compared with noncalculated constituents, the SEL of the carbohydrate fractions OA and NDSF were much higher (Tables 1 and 2), whereas that of NDSC was relatively low. Considering both the SEL values and the overall performance of NIRS equations for OA (unsuccessful), NDSF (moderately successful), and NDSC (successful) in a combined sample set, the SEL of NDSF might have been overestimated. As Harris (1991) explained, the aforementioned formula used to calculate this SEL provides a more probable estimate than the one achieved by simply adding all the individual errors, but it could be greater than the error calculated from duplicate analyses. The overestimated error of NDSF was mainly transferred from the SEL of EIROM in the calculations, similar to that for the SEL of OA.

NIRS Prediction of Related Constituents. By using the combined calibration set that included both forage species, it was possible to generate robust NIRS equations, with an $\mathrm{R}_{\mathrm{P}}^{2}$ of 0.91 to 0.99 and an RPD of 3.3 to 8.4 (Table 3), to predict DM and NDF, and other constituents (OM, CP, EE, NDROM, NDRCP, and EIRCP) that are used to calculate 3 carbohydrate fractions (OA, NDSF, and NDSC). Compared with other results of NIRS applications in forages (Roberts et al., 2004), our current EE estimation was more accurate $\left(\mathrm{R}_{\mathrm{P}}^{2}=0.91, \mathrm{RPD}=3.3\right)$; few studies have reported NIRS predictions of EE concentration with $\mathrm{R}^{2}$ $>0.90$ (Murray and Hall, 1983; Roberts et al., 2004). The NDF NIRS model was also more accurate, as evidenced by an RPD of 8.4 and an $R_{P}^{2}$ of 0.99 in validation. The high RPD of NDF partly resulted from the highest standard deviation value $(140.5 \mathrm{~g} / \mathrm{kg}$ of DM) of the combined validation set.
The NDROM and NDRCP constituents of the combined set of alfalfa and timothy samples were predicted with a high degree of accuracy $\left(\mathrm{R}_{\mathrm{P}}^{2}=0.96, \mathrm{RPD} \geq 4.3\right.$; Table 3). There are few reports of NIRS prediction of NDROM, whereas studies on the prediction of NDRCP have reported differing degrees of accuracy. Hoffman et al. (1999) and Mentink et al. (2006) observed lowquality calibration $\left(\mathrm{R}^{2}=0.71\right.$ and 0.52 , respectively) of NDRCP for grass silage and TMR samples. However, Valdés et al. (2006) reported that neutral detergentinsoluble nitrogen in heterogeneous permanent meadows was successfully predicted by NIRS, with 1-VR of 0.91 and RPD of 3.33. Nie et al. (2008) obtained a poor $\mathrm{NDRCP}$ prediction $\left(\mathrm{R}_{\mathrm{P}}^{2}=0.75, \mathrm{RPD}=1.98\right)$ in alfalfa based on partial least squares regression, but greater accuracy $\left(\mathrm{R}_{\mathrm{P}}^{2}=0.90, \mathrm{RPD}=3.08\right)$ was achieved with the support vector regression method. The high accuracy of the NDROM prediction observed in the current experiment may be due to its strong correlation $(\mathrm{r}=$ $0.97, \quad P<0.001$, and $\mathrm{n}=150$ ) with NDF. Accurate NIRS equations for NDRCP possibly resulted from the wide range of 6.1 to $59.7 \mathrm{~g} / \mathrm{kg}$ of DM and relatively low SEL of $1.2 \mathrm{~g} / \mathrm{kg}$ of DM for the calibration set (Table 2).

The EIROM was less accurately predicted, with an $\mathrm{R}_{\mathrm{P}}^{2}$ of 0.75 and an RPD of 1.9 (Table 3). This was probably due to the higher laboratory error (SEL = $24.1 \mathrm{~g} / \mathrm{kg}$ of DM; Table 2) of EIROM compared with all other noncalculated carbohydrate fractions. However, EIRCP, which is another EIR-based constituent, was accurately predicted, with an $\mathrm{R}_{\mathrm{P}}^{2}$ of 0.93 and an RPD of 3.2; this successful prediction could be partly explained by the strong correlation between EIRCP and $\mathrm{CP}$ concentration $(\mathrm{r}=0.91, \quad P<0.001$, and $\mathrm{n}=$ $150)$.

\section{RER for Calibration Versus NIRS Performance}

Williams (2001) calculated the RER and RPD for his validation set of samples and classified his NIRS predictions based on these statistics. He reported that a validation RER value greater than 13 indicated good NIRS performance. In the present study, we suggested calculating the RER statistic, which is equal to the range divided by the SEL, for the calibration set. Our results for combined species showed that all constituents with calibration RER values greater than 13 were successfully predicted by NIRS (Tables 2 and 3). The predictions for OA and EIROM were unsuccessful, with low calibration RER values of 3.5 and 9.0, respectively (Table 2). Although the calibration RER value was 

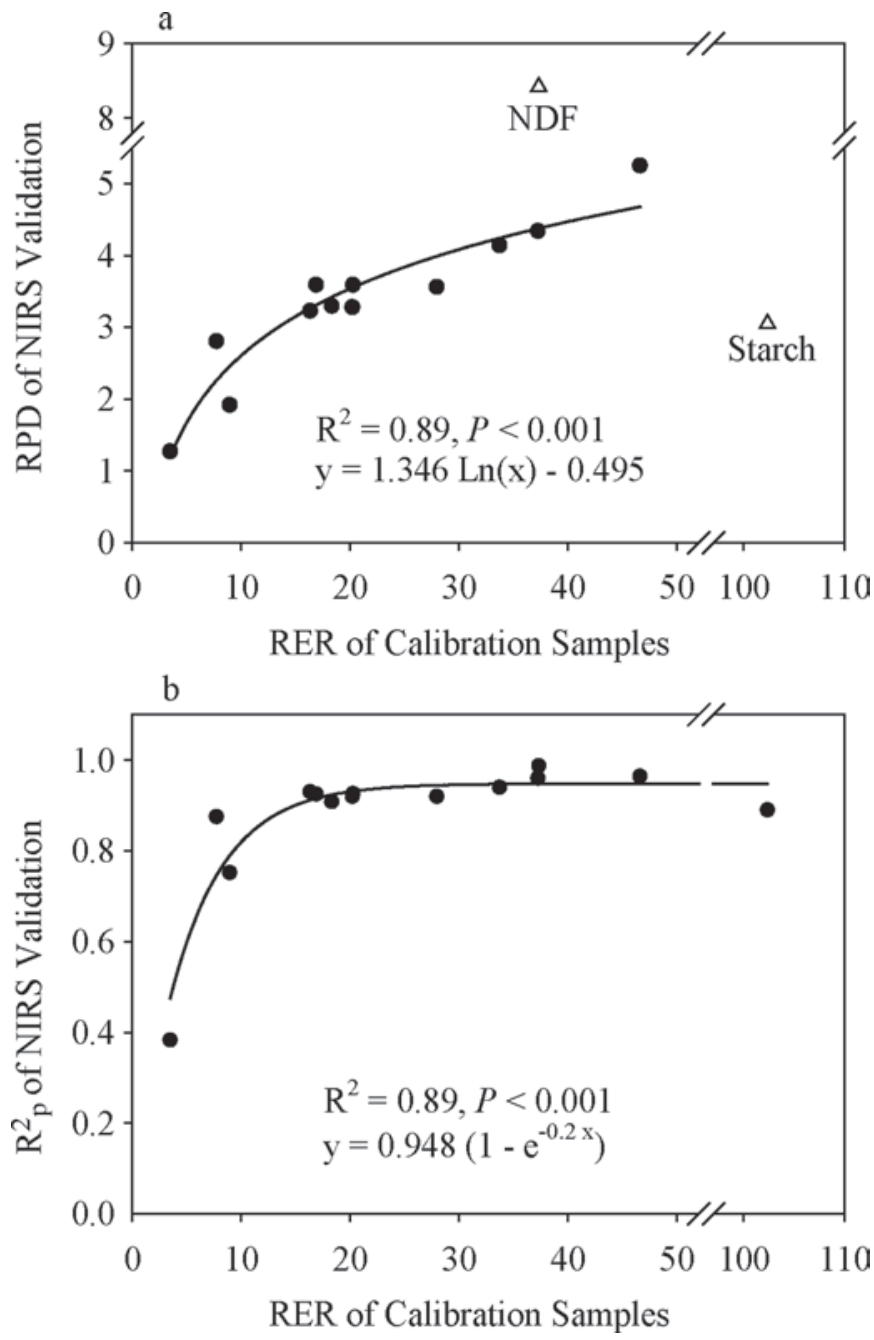

Figure 2. Relationships between the ratio of error range $[\mathrm{RER}=$ range of values (maximum - minimum)/standard error of laboratory (SEL)] for the calibration set and the ratio of prediction to deviation $\{\mathrm{RPD}=$ standard deviation/standard error of prediction corrected for the bias $[\operatorname{SEP}(\mathrm{C})]\}$ for the validation set (a) and between the calibration RER and the coefficient of determination of prediction $\left(\mathrm{R}_{\mathrm{P}}^{2}\right)$ for the validation set (b) for all constituents (solid circle) predicted by NIRS by using the combined alfalfa and timothy sample set. Solid lines represent regressions, excluding triangle symbols.

only 7.7 (Table 2) for NDSF, the NIRS prediction of this carbohydrate fraction was moderately successful $\left(\mathrm{R}_{\mathrm{P}}^{2}=0.88, \mathrm{RPD}=2.8\right.$; Table 3$)$. Successful NIRS prediction of carbohydrate fractions can therefore be obtained when the calibration RER values are greater than 13; when RER values are less than 13, NIRS prediction could be either moderately successful or unsuccessful. The relationships between the RER of the calibration set and RPD and $\mathrm{R}_{\mathrm{P}}^{2}$ of the validation set of combined alfalfa and timothy samples are presented in
Figure 2. Two exceptions appear in the RER-RPD graph (Figure 2a): NDF and starch. Because of the much lower SEL and the wide range of values for starch compared with other constituents, the RER value for starch was inflated, whereas the NIRS performance values maintained a normal degree of accuracy. The exception of NDF in the RER-RPD graph (Figure 2a) was caused by its high RPD value (8.4), which resulted from the greatest standard deviation value $(140.5 \mathrm{~g} / \mathrm{kg}$ of DM) in the validation set (Table 3). When these exceptions were excluded from the RER-RPD graph (Figure 2a), both coefficients of determination of the 2 regressions in Figure 2 equaled $0.89(P<0.001)$. Based on separate equations for each species, the statistics are lower; the coefficient of determination of the relationship between the calibration RER and the RPD of the validation set was 0.75 for timothy and 0.67 for alfalfa, whereas the coefficient of determination of the relationship between calibration RER and the $R_{\mathrm{P}}^{2}$ of the NIRS validation was 0.85 for timothy and 0.87 for alfalfa (data not shown). The calibration RER value is a quantified expression of the influence on NIRS performance of laboratory error and the range of concentrations of a given constituent in the calibration set of samples. It is therefore a potentially useful indicator of subsequent NIRS performance.

\section{CONCLUSIONS}

Results of the current study confirmed that all carbohydrate fractions and related constituents measured according to Hall et al. (1999), except OA and EIROM, could be predicted by using NIRS. Combining both timothy and alfalfa sample sets improved NIRS prediction statistics ( $\mathrm{R}^{2}, \mathrm{RPD}$, and slope), whereas many carbohydrate fractions were unsuccessfully predicted by separate NIRS equations for each species. Improved predictions with the combined sample database were due to wider variations, as indicated by the greater range of standard deviation values. The unsuccessful prediction of OA, as well as the moderately successful prediction of NDSF concentration, was mainly attributed to the laboratory error associated with the EIROM analysis used to calculate these fractions. A greater range of values and more precise laboratory analyses, especially for EIROM, could help to improve NIRS prediction for carbohydrate fractions and their related constituents. The calibration RER value was highly correlated with the NIRS performance parameters $R_{P}^{2}$ and RPD and could therefore be used to evaluate the possibility of obtaining successful equations before any NIRS work. 


\section{ACKNOWLEDGMENTS}

The authors acknowledge the technical assistance of Mario Laterrière and Danielle Mongrain. The authors also thank Cargèle Nduwamungu for his comments on an earlier version of this manuscript. We also acknowledge the assistance of Christina McRae, from Editworks, for the structural editing of this manuscript. This study was funded by the "Action concertée AAC-FQRNTMAPAQ-NOVALAIT Inc. (2007-2011)," and the MOE (Ministry of Education of China)-AAFC (Agriculture and Agri-Food Canada) PhD research program.

\section{REFERENCES}

AOCS. 1998. Official Methods and Recommended Practices of the AOCS. 5th ed. American Oil Chemists' Society, Champaign, IL.

Batten, G. D., A. B. Blakeney, V. B. McGrath, and S. Ciavarella. 1993. Non-structural carbohydrate: Analysis by near infrared reflectance spectroscopy and its importance as an indicator of plant growth. Plant Soil 155:243-246.

Blakeney, A. B., and L. L. Mutton. 1980. A simple colorimetric method for the determination of sugar in fruit and vegetables. J. Sci. Food Agric. 31:889-897.

Brink, G. E., and G. C. Marten. 1986. Analysis of alfalfa root carbohydrate concentration by near infrared reflectance spectroscopy. Crop Sci. 26:159-161.

Brown, W. F., C. K. Piacitelli, and P. Mislevy. 1987. Near infrared reflectance analysis of total nonstructural carbohydrate concentration in tropical grasses. Crop Sci. 27:786-788.

Cozzolino, D., and A. Morón. 2006. Potential of near-infrared reflectance spectroscopy and chemometrics to predict soil organic carbon fractions. Soil Tillage Res. 85:78-85.

Dunn, B. W., H. G. Beecher, G. D. Batten, and S. Ciavarella. 2002. The potential of near-infrared reflectance spectroscopy for soil analysis - A case study from the Riverine Plain of south-eastern Australia. Aust. J. Exp. Agric. 42:607-614.

Fairbrother, T. E., and G. E. Brink. 1990. Determination of cell wall carbohydrates in forages by near infrared reflectance spectroscopy. Anim. Feed Sci. Technol. 28:293-302.

Fonseca, C. E. L., J. L. Hansen, E. M. Thomas, A. N. Pell, and D. R. Viands. 1999. Near infrared reflectance spectroscopy prediction and heritability of neutral detergent-soluble fiber in alfalfa. Crop Sci. 39:1265-1270.

Goering, H. K., and P. J. Van Soest. 1970. Forage Fiber Analysis (Apparatus, Reagents, Procedures and Some Applications). Agric. Handbook No. 379. ARS-USDA, Washington, DC.

Gossen, B. D. 1994. Field response of alfalfa to harvest frequency, cultivar, crown pathogens, and soil fertility: II. Crown rot. Agron. J. 86:88-93.

Hall, M. B., W. H. Hoover, J. P. Jennings, and T. K. M. Webster. 1999. A method for partitioning neutral detergent-soluble carbohydrates. J. Sci. Food Agric. 79:2079-2086.

Harris, D. C. 1991. Quantitative Chemical Analysis. 3rd ed. W. H. Freeman and Company, New York, NY.

Hoffman, P. C., N. M. Brehm, L. M. Bauman, J. B. Peters, and D. J. Undersander. 1999. Prediction of laboratory and in situ protein fractions in legume and grass silages using near-infrared reflectance spectroscopy. J. Dairy Sci. 82:764-770.
Isaac, R. A., and W. C. Johnson. 1976. Determination of total nitrogen in plant tissue, using a block digestor. J. Assoc. Off. Anal. Chem. 59:98-100.

Kim, H. O., and P. C. Williams. 1990. Determination of starch and energy in feed grains by near-infrared reflectance spectroscopy. J. Agric. Food Chem. 38:682-688.

Lachat Instruments. 2008. Methods list for automated ion analyzers (flow injection analyses, ion chromatography). http://www lachatinstruments.com/applications/Methods.asp Accessed Oct. 2008.

Leiva, E., M. B. Hall, and H. H. Van Horn. 2000. Performance of dairy cattle fed citrus pulp or corn products as sources of neutral detergent-soluble carbohydrates. J. Dairy Sci. 83:2866-2875.

Marten, G. C., J. L. Halgerson, and J. H. Cherney. 1983. Quality prediction of small grain forages by near infrared reflectance spectroscopy. Crop Sci. 23:94-101.

Mentink, R. L., P. C. Hoffman, and L. M. Bauman. 2006. Utility of near-infrared reflectance spectroscopy to predict nutrient composition and in vitro digestibility of total mixed rations. J. Dairy Sci. 89:2320-2326.

Murray, I., and A. P. Hall. 1983. Animal feed evaluation by use of near infrared reflectance (NIR) spectrocomputer. Anal. Proc. $20: 75-79$

Naes, T., T. Isaksson, T. Fearn, and T. Davies. 2002. A User-Friendly Guide to Multivariate Calibration and Classification. NIR Publications, Chichester, UK

NRC. 2001. Nutrient Requirements of Dairy Cattle. 7th rev. ed. Natl. Acad. Press, Washington, DC.

Nie, Z., J. Han, T. Liu, and X. Liu. 2008. Application of support vector machine method in prediction of alfalfa protein fractions by near infrared reflectance spectroscopy. J. Dairy Sci. 91:2361-2369.

Norris, K. H., R. F. Barnes, J. E. Moore, and J. S. Shenk. 1976 Predicting forage quality by infrared reflectance spectroscopy. J. Anim. Sci. 43:889-897.

Roberts, C. A., J. Stuth, and P. Flinn. 2004. Analysis of forages and feedstuffs. Pages 231-267 in Near-Infrared Spectroscopy in Agriculture. C. A. Roberts, J. Workman, and J. B. Reeves, ed. Am. Soc. Agron., Crop Sci. Soc. Am., Soil Sci. Soc. Am., Madison, WI

Shenk, J. S., and M. O. Westerhaus. 1991. Population definition, sample selection, and calibration procedures for near infrared reflectance spectroscopy. Crop Sci. 31:469-474.

Shenk, J. S., and M. O. Westerhaus. 1994. The application of near infrared reflectance spectroscopy (NIRS) to forage analysis. Pages 406-499 in Forage Quality Evaluation and Utilization. G. C. Fahey, ed. Am. Soc. Agron., Crop Sci. Soc. Am., Soil Sci. Soc. Am., Madison, WI.

Sinnaeve, G., P. Dardenne, R. Agneessens, and R. Biston. 1994. The use of near infrared spectroscopy for the analysis of fresh grass silage. J. Near Infrared Spectrosc. 2:79-84.

Valdés, C., S. Andrés, F. J. Giráldez, R. García, and A. Calleja. 2006. Potential use of visible and near infrared reflectance spectroscopy for the estimation of nitrogen fractions in forages harvested from permanent meadows. J. Sci. Food Agric. 86:308-314.

Van Soest, P. J. 1967. Development of a comprehensive system of feed analyses and its application to forages. J. Anim. Sci. 26:119128.

Welle, R., W. Greten, B. Rietmann, S. Alley, G. Sinnaeve, and P. Dardenne. 2003. Near-infrared spectroscopy on chopper to measure maize forage quality parameters online. Crop Sci. 43:1407-1413.

Williams, P. C. 2001. Implementation of near-infrared spectroscopy Pages 145-169 in Near-Infrared Technology in the Agricultural and Food Industries. 2nd ed. P. C. Williams and K. Norris, ed. Am. Assoc. Cereal Chem., St. Paul, MN. 